\title{
COBERTURA VACINAL DE CRIANÇAS ATÉ UM ANO DE IDADE, EVENTOS ADVERSOS E COMPOSIÇÃO DAS VACINAS NOS ANOS DE 2014 A 2018 NO BRASIL
}

\author{
VACCINATION COVERAGE AMONG CHILDREN UP TO ONE YEAR \\ OLD, ADVERSE EFFECTS AND COMPOSITION OF VACCINES \\ FROM 2014 TO 2018 IN BRAZIL
}

\author{
Jacobsen, F. T ${ }^{1}$, Velasquez, L. $\mathrm{G}^{2}$ \\ Afiliações: 1- Curso de Farmácia da Universidade Paranaense - UNIPAR. 2- Mestrado Profissional em Plantas Medicinais e Fitoterápicos \\ na Atenção Básica da Universidade Paranaense - UNIPAR. \\ Endereço do autor de correspondência com Av. Júlio Assis Cavalheiro 2000, bairro Industrial, Francisco Beltrão, Paraná, Brasil. CEP: \\ 85601-000. leo@prof.unipar.br.
}

\section{Resumo}

Vacinas são imunobiológicos preparados a partir de microrganismos vivos ou mortos. No Brasil, as vacinas começaram a ser utilizadas no século XIX para controle de doenças. Hoje em dia, as vacinas conferem também erradicação e eliminação de doenças imunopreveníveis. Apesar de seguras, podem causar eventos adversos, sendo a maior parte considerada leve e podendo ter relação com a aplicação ou alguns componentes. Este estudo pretendeu analisar a cobertura vacinal de crianças menores de 1 ano de idade no Brasil no período de 2014 a 2018 e comparar com os Eventos Adversos Pós-vacinação (EAPV) e composição vacinal. Foi realizado um estudo transversal documental da cobertura vacinal das cinco regiões brasileiras, utilizando o banco de dados do DATASUS, das vacinas obrigatórias para crianças de até 12 meses de idade, realizou-se, também, um levantamento de casos de EAPV nos Boletins Epidemiológicos e da composição vacinal nos Manuais e Guias do Ministério da Saúde. As análises mostraram que apenas duas vacinas (BCG e tríplice viral) tiveram média nacional da cobertura superior a $95 \%$. A vacina tríplice viral apresentou mais eventos adversos, sendo a maior parte leve e tendo possível relação com a diminuição da cobertura. As maiores coberturas vacinais ocorreram no Centro-oeste e as menores nas regiões Norte e Sul, podendo ter relação com a desigualdade socioeconômica e outras variáveis. Tendo em vista a diminuição da cobertura vacinal e o retorno de doenças erradicadas, faz-se necessário investir em campanhas de vacinação e conscientizar a população sobre a importância das vacinas e possíveis eventos adversos.

Palavras-chave: Cobertura vacinal; Eventos Adversos Pós-vacinação; Composição das vacinas.

\section{Abstract}

Vaccines are immunobiological prepared from living or dead microorganisms. In Brazil, vaccines began to be used in the 19th century for disease control. Nowadays, vaccines also confer eradication and elimination of immunopreventable diseases. Although safe, they can cause adverse events, most of which are considered mild and may be related to the application or some components. This study aimed to analyze the vaccination coverage of children under 1 year of age in Brazil from 2014 to 2018 and to compare with Adverse Events Following Immunization (AEFI) and vaccine composition. A cross-sectional documentary study of the vaccination coverage of the five Brazilian regions was carried out using the DATASUS database of compulsory vaccines for children up to 12 months of age, vaccine composition in the Manuals and Guides of Ministério da Saúde. Analyzes showed that only two vaccines (BCG and triple viral) had a national average coverage greater than $95 \%$. The triple viral vaccine presented more adverse events, most of them being mild and possibly related to decreased coverage. The highest vaccination coverage occurred in the Midwest and the lowest in the North and South and may be related to socioeconomic inequality and other variables. With a view to reducing vaccination coverage and the return of eradicated diseases, it is necessary to invest in vaccination campaigns and raise awareness about the importance of vaccines and possible adverse events.

Keywords: Vaccinal coverage; Adverse Events Following Immunization; Composition of vaccines. 


\section{Introdução}

Vacinas são feitas a partir de preparação de microrganismos ou parte deles, podendo ser vivos ou mortos. Os vivos são obtidos de cepas naturais e os microrganismos são atenuados por passagens em meios de cultura especiais; como exemplos, há as vacinas contra a poliomielite (oral), rotavírus, caxumba, rubéola, varicela e febre amarela. Por provocarem estímulo ao sistema imune similar ao natural, conferem grande capacidade protetora e imunidade em longo prazo, portanto são utilizadas em menor número e doses que as vacinas inativadas ${ }^{1}$.

A primeira vacina foi criada por Edward Jenner que, a partir das suas observações, percebeu que as ordenhadoras não desenvolviam varíola, pois tinham contato com as pústulas de cowpox, uma doença semelhante à varíola que atinge o gado. Jenner começou a imunizar crianças, mas ainda havia muita resistência, principalmente da classe médica e dos religiosos. Apesar disso, em pouco tempo a vacina se popularizou pelo mundo. Devido a forma de imunização, que na época era feita "braço a braço", em 1820 vários imunizados contraíram varíola e ninguém mais acreditava em sua eficácia. Foi então que descobriram que a proteção não era eterna e era preciso revacinar- se. Em 1885, Louis Pasteur inoculou medula de coelho contaminado com raiva em uma criança que havia sido mordida por um cachorro raivoso e a criança não contraiu a doença, surgindo, dessa maneira, a primeira vacina seguindo uma metodologia científica, que revolucionou a ciência ao desenvolver um imunizante produzido por um método que podia ser generalizado ${ }^{2}$.

No Brasil, no início do século XIX, as vacinas começaram a ser usadas como medida de controle de doenças. Em 1973, foi criado o Programa Nacional de Imunizações (PNI) que gerencia a política nacional de vacinações e tem como missão o controle, a erradicação e a eliminação de doenças imunopreveníveis, principalmente durante a infância ${ }^{3,4}$.

A maioria das vacinas que compõe o Calendário Nacional de Vacinação é destinada a crianças. No total, elas são 12, divididas em 25 doses até os 10 anos de idade. Ao nascer, a criança deve receber a $\mathrm{BCG}$ e a contra Hepatite B. Aos dois e aos quatro meses, as vacinas são: Pentavalente, Poliomielite inativada, Pneumocócica 10 valente e Rotavírus. Aos três e aos cinco meses, apenas a Meningocócica. As terceiras doses da Pentavalente e da Poliomielite inativada são feitas aos seis meses. Aos nove meses, apenas a Febre Amarela e, aos 12, a 
Tríplice Viral, a Pneumocócica 10 valente e a Meningocócica C. Aos 15 meses, a DTP, a Poliomielite oral, a Hepatite A e a Tetra viral. Aos quatro anos, a DTP, a Poliomielite oral e a Varicela. A vacina do HPV é disponível para meninas dos 9 aos 14 anos e para meninos dos 11 aos 14. O reforço da Meningocócica C é feito dos 11 aos 14 anos. Dos 10 aos 19 anos, dos 20 aos 59 anos e aos acima de 60 anos estão disponíveis as vacinas da Hepatite B, Febre Amarela, Dupla Adulto, Tríplice Viral e Pneumocócica 23 valente 5 .

Segundo o Boletim Epidemiológico de Vacinas de $2015^{6}$, em 41 anos do Programa Nacional de Imunização (PNI), muitas conquistas importantes ocorreram, como a erradicação da poliomielite e a eliminação da circulação de vírus autóctones do sarampo e da rubéola. Também houve redução da morte por doenças imunopreveníveis nas últimas décadas, o que levou à credibilidade da sociedade brasileira, que pode ser observada pela adesão da população à vacinação conferida pelas coberturas vacinais, principalmente as incluídas no calendário de vacinação da criança.

As vacinas são os imunobiológicos mais seguros e eficazes, além de possuírem custo benefício favorável. Todavia, após a sua administração, pode haver eventos adversos, os quais podem ser sistêmicos, moderados ou graves e ter relação com as vacinas, com os indivíduos e a técnica de aplicação. Apesar das técnicas de produção das vacinas serem sempre aperfeiçoadas, essas possuem agentes infecciosos atenuados ou inativados, além de alguns componentes que podem induzir aos eventos adversos ${ }^{7}$.

Em 2016, foi observada uma redução da cobertura vacinal, principalmente da vacina Tríplice Viral, cuja causa pode estar relacionada a Eventos Adversos Pós-Vacinação (EAPV), isso contribuiu para o retorno da circulação dos vírus atenuados, principalmente do sarampo que de junho a agosto de 2019 teve confirmado um total de 2.331 casos no Brasil ${ }^{6,8,9}$. Além disso, observa-se na mídia uma onda de informações erradas acerca das vacinas que vão desde o surgimento de patologias como o autismo, por exemplo, até informações de que as vacinas não funcionam. Cabe ressaltar ainda, que os eventos adversos à vacinação podem ainda ter relação com a composição delas, já que existem indivíduos que apresentam quadros de hipersensibilidade a determinados tipos de compostos, ou ainda, por questões de toxicidade 
de alguns componentes, como é o caso do timerosal, por exemplo ${ }^{10}$.

Diante do exposto, o presente trabalho teve como objetivo analisar a cobertura vacinal de crianças menores de 1 ano de idade no Brasil no período de 2014 a 2018 e compará-la com os Eventos Adversos Pós-vacinação (EAPV) e com a composição das vacinas.

\section{Métodos}

O presente trabalho se trata de um estudo transversal retrospectivo, no qual, no período de setembro a novembro de 2019, realizou-se um levantamento da cobertura vacinal nas cinco regiões do Brasil nos anos de 2014 a 2018, através do banco de dados do DATASUS, levando em consideração as vacinas de rotina para crianças de até 12 meses de idade, segundo o Caderno Nacional de Vacinas do Ministério da Saúde. Além das vacinas, realizou-se o levantamento de casos de Eventos Adversos Pós-Vacinação (EAPV) nos Boletins Epidemiológicos, assim como a composição de cada vacina nos Manuais e Guias do Ministério da Saúde.

Os resultados foram organizados em tabelas e gráficos, possibilitando a análise e a comparação com os EAPV.

\section{Resultados}

No período de 2014 a 2018, o Brasil apresentou uma cobertura vacinal de aproximadamente 86\%, sendo que em 2014 e 2015 essa cobertura foi superior a $90 \%$ e a partir de 2016 foi inferior a $85 \%$. A figura 1 abaixo retrata a cobertura vacinal brasileira dividida por regiões nos anos de 2014 a 2018.

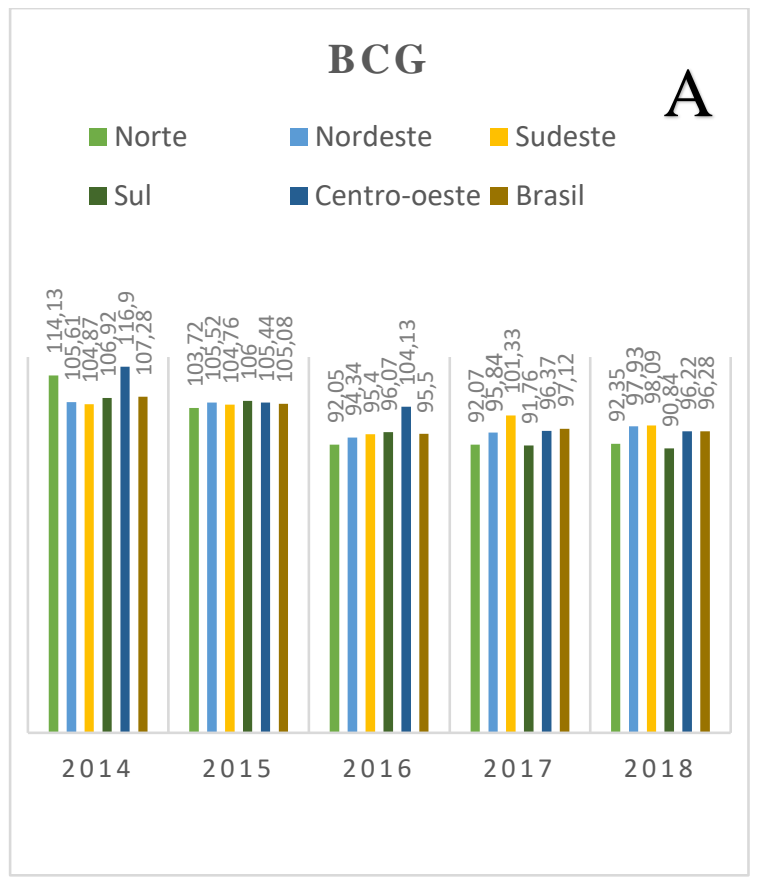


Acta Elit Salutis- AES - (2019) v.1 (1)

ISSN online 2675-1208 - Artigo Original
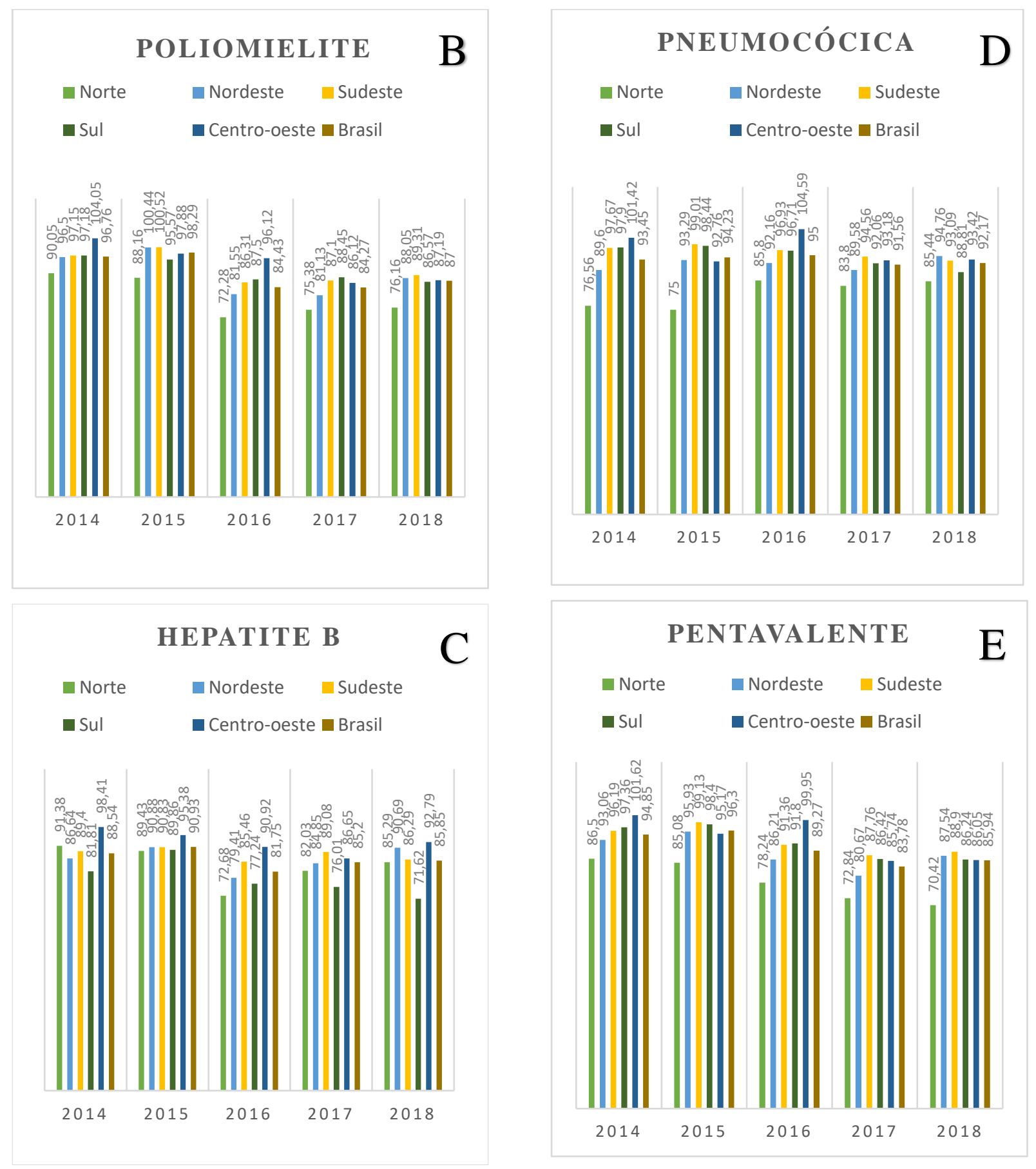
Acta Elit Salutis- AES - (2019)v.1 (1)

ISSN online 2675-1208 - Artigo Original
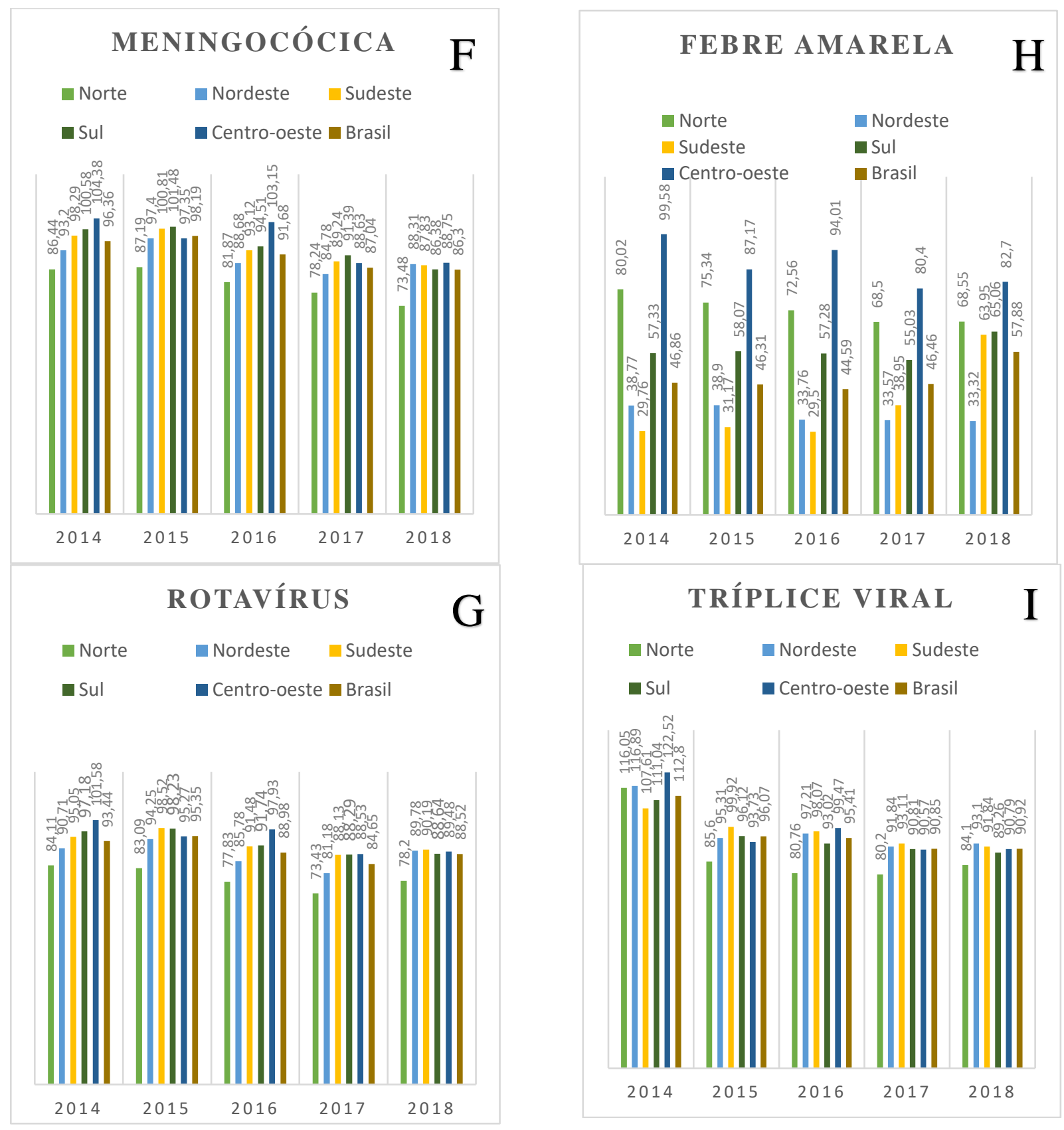

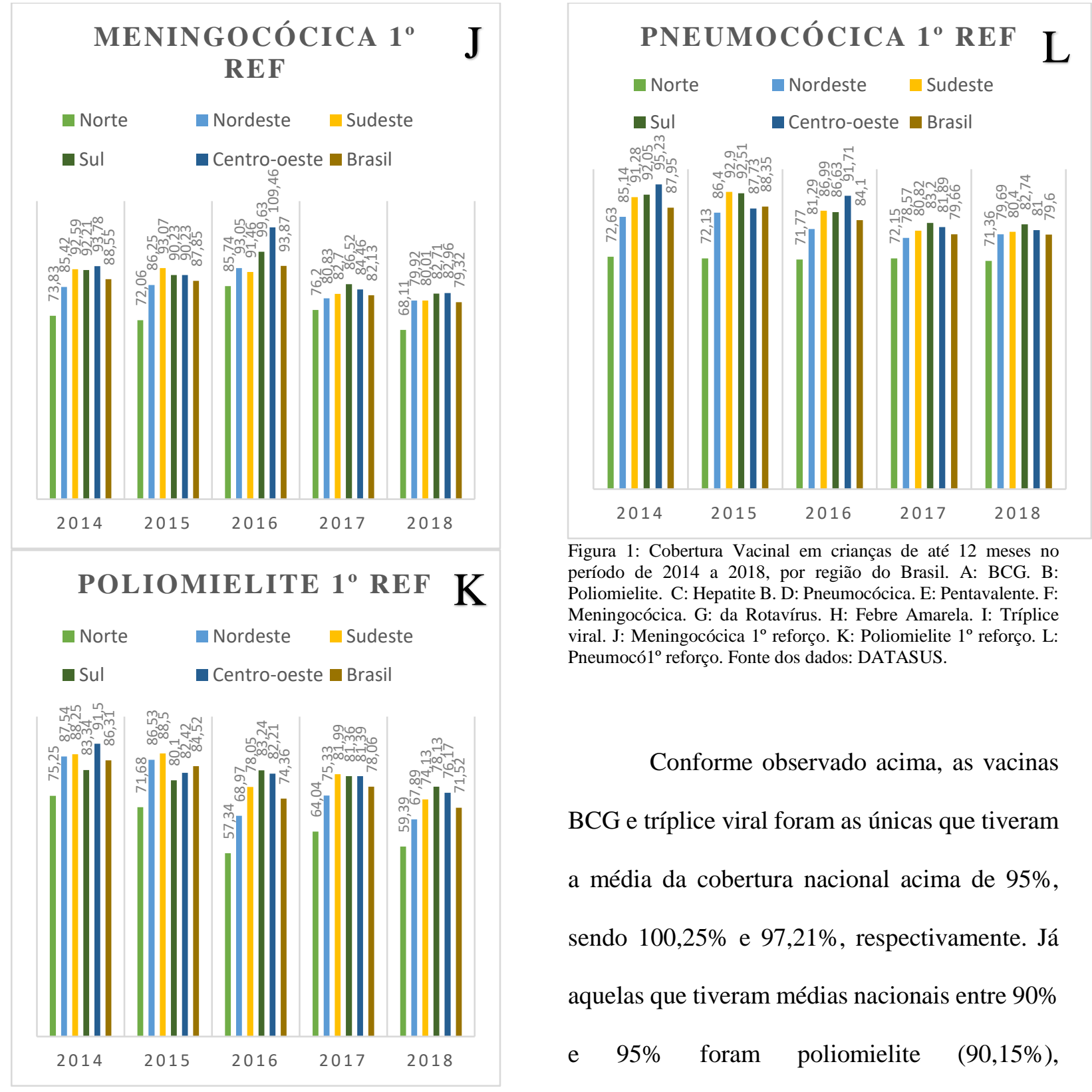

Figura 1: Cobertura Vacinal em crianças de até 12 meses no período de 2014 a 2018, por região do Brasil. A: BCG. B: Poliomielite. C: Hepatite B. D: Pneumocócica. E: Pentavalente. F: Meningocócica. G: da Rotavírus. H: Febre Amarela. I: Tríplice viral. J: Meningocócica $1^{\circ}$ reforço. K: Poliomielite $1^{\circ}$ reforço. L: Pneumocó $1^{\circ}$ reforço. Fonte dos dados: DATASUS.

Conforme observado acima, as vacinas BCG e tríplice viral foram as únicas que tiveram a média da cobertura nacional acima de 95\%, sendo $100,25 \%$ e $97,21 \%$, respectivamente. Já aquelas que tiveram médias nacionais entre $90 \%$ e $95 \%$ foram poliomielite $(90,15 \%)$, pneumocócica $\quad(93,28 \%), \quad$ pentavalente (90,03\%), meningocócica $(91,91 \%)$ e rotavírus $(90,19 \%)$. As vacinas que apresentaram média inferior a $90 \%$ foram hepatite B $(86,45 \%)$, febre amarela (48,42\%), meningocócica $1^{\circ}$ ref. $(86,34 \%)$, poliomielite $1^{\circ}$ ref. $(78,95 \%)$ e pneumocócica $1^{\circ}$ ref. $(83,93 \%)$.

Quanto à cobertura vacinal por região, a região Sul apresentou as menores médias nas 
vacinas BCG $(98,32 \%)$ e hepatite B $(79,3 \%)$. As menores médias observadas na região Norte compreendem às vacinas poliomielite $(80,4 \%)$, pneumocócica $(81,32 \%), \quad$ pentavalente (78,61\%), meningocócica $(81,44 \%)$, rotavírus (79,33\%), meningocócica $1^{\circ}$ ref. $(75,19 \%)$, poliomielite $1^{\circ}$ ref. $(65,54 \%)$ e pneumocócica $1^{\circ}$ ref. $(72,01 \%)$. A menor média da vacina da febre amarela foi na região Nordeste $(35,66 \%)$. A região Centro-oeste obteve as maiores médias de cobertura em todas as vacinas, sendo BCG $103,81 \%$, poliomielite $94,27 \%$, hepatite $\mathrm{B}$ 92,83\%, pneumocócica 97,04\%, pentavalente 93,7\%, meningocócica 96,45\%, rotavírus $94,56 \%$, febre amarela $88,77 \%$, tríplice viral 99,41\%, meningocócica $1^{\circ}$ ref. 92,19\%, poliomielite $1^{\circ}$ ref. $82,74 \%$ e pneumocócica $1^{\circ}$ ref. 87,51\%. Além das maiores médias, a região Centro-oeste obteve as maiores coberturas de todas as vacinas também. Sendo BCG 116,9\%, poliomielite 104,05\%, hepatite B 98,41\%, pentavalente 101,62\% meningocócica 104,38\%, rotavírus 101,58\%, febre amarela 99,58\%, tríplice viral $122,53 \%$, poliomielite $1^{\circ}$ ref. $91,5 \%$ e pneumocócica $1^{\circ}$ ref. 95,23\% todas em 2014 . As vacinas pneumocócica e meningocócica $1^{\circ}$ ref. tiveram a maior cobertura em 2016, sendo $104,59 \%$ e $109,48 \%$, respectivamente. A região
Norte também apresentou as menores coberturas na maior parte das vacinas, sendo poliomielite 72,28\% em 2016, pneumocócica 75\% em 2015, pentavalente 70,42\% em 2018, meningocócica 73,48\% em 2018, rotavírus $73,43 \%$ em 2017 , tríplice viral 80,2\% em 2017, meningocócica $1^{\circ}$ ref. $68,11 \%$ em 2018 , poliomielite $1^{\circ}$ ref. $57,34 \%$ em 2016 e pneumocócica $1^{\circ}$ ref. 71,36\% em 2018. A região Sul apresentou as menores coberturas nas demais vacinas, sendo BCG 90,84\% em 2018, hepatite B 71,62\% em 2018 e febre amarela 29,5\% em 2016. 
A tabela 1, a seguir, traz informações acerca da composição das vacinas supracitadas de 2014 a 2018.

\begin{tabular}{|c|c|c|c|c|}
\hline Vacina & Composição 2014 & Composição 2016/2017 & Composição 2017/2018 & Referências $^{1,11,12}$ \\
\hline BCG & $\begin{array}{l}\text { Cepas do Mycobacterium } \\
\text { bovis, atenuadas com } \\
\text { glutamato de sódio. Subcepa: } \\
\text { Moureau-Rio de Janeiro }\end{array}$ & $\begin{array}{l}\text { Bacilos atenuados do } \\
\text { Mycobacterium bovis. }\end{array}$ & $\begin{array}{l}\text { Bacilos atenuados do } \\
\text { Mycobacterium bovis. }\end{array}$ & $\begin{array}{l}\text { Manual dos Centros de Referência } \\
\text { para Imunobiológicos Especiais } \\
\text { Guia prático de vacinas } 2016 / 2017 \\
\text { Guia prático de vacinas } 2017 / 2018\end{array}$ \\
\hline Hepatite B & $\begin{array}{l}\text { Antígeno recombinante de } \\
\text { superfície (HBsAg), que é } \\
\text { purificado por métodos FQ e } \\
\text { adsorvido por hidróxido de } \\
\text { alumínio, tendo o timerosal } \\
\text { como conservante. }\end{array}$ & $\begin{array}{l}\text { Subunidades do vírus da } \\
\text { hepatite B (HBsAg) } \\
\text { produzidas em células de } \\
\text { fungo ( } S \text {. cerevisiae) por } \\
\text { recombinação genética. } \\
\text { Contém alumínio. }\end{array}$ & $\begin{array}{l}\text { Subunidades do vírus da } \\
\text { hepatite B (HBsAg) } \\
\text { produzidas em células de } \\
\text { fungo ( } \text { S. cerevisiae) por } \\
\text { recombinação genética. } \\
\text { Contém alumínio. }\end{array}$ & $\begin{array}{l}\text { Manual dos Centros de Referência } \\
\text { para Imunobiológicos Especiais } \\
\text { Guia prático de vacinas } 2016 / 2017 \\
\text { Guia prático de vacinas 2017/2018 }\end{array}$ \\
\hline Pentavalente & $\begin{array}{l}\text { Combinação de toxoides } \\
\text { purificados de difteria e tétano, } \\
\text { suspensão celular inativada de } \\
\text { Bordetella pertussis (células } \\
\text { inteiras), antígeno de } \\
\text { superfície da hepatite B } \\
\text { (recombinante) e } \\
\text { oligossacarídeos conjugados } \\
\text { de Haemophilus influenzae b } \\
\text { (conjugada). Adjuvante: } \\
\text { fosfato de alumínio } \\
\text { Conservante: tiomersal. }\end{array}$ & $\begin{array}{l}\text { Três ou dois antígenos } \\
\text { purificados de pertussis } \\
\text { (acelular); toxoides tetânico e } \\
\text { diftérico; } 3 \text { tipos de vírus de } \\
\text { poliomielite inativados; } \\
\text { polissacarídeos do hemófilo } \\
\text { conjugado ao toxoide } \\
\text { tetânico; na hexavalente, } \\
\text { HBsAg purificado produzido } \\
\text { por recombinação genética } \\
\text { em célula de levedura. } \\
\text { Contém alumínio e } \\
\text { neomicina. Eficácia } \\
\text { comparável às apresentações } \\
\text { isoladas com menor } \\
\text { incidência de eventos } \\
\text { adversos }\end{array}$ & $\begin{array}{l}\text { Três ou dois antígenos } \\
\text { purificados de pertussis } \\
\text { (acelular); toxoides tetânico e } \\
\text { diftérico; } 3 \text { tipos de vírus de } \\
\text { poliomielite inativados; } \\
\text { polissacarídeos do hemófilo } \\
\text { conjugado ao toxoide } \\
\text { tetânico; na hexavalente, } \\
\text { HBsAg purificado produzido } \\
\text { por recombinação genética } \\
\text { em célula de levedura. } \\
\text { Contém alumínio e } \\
\text { neomicina. Eficácia } \\
\text { comparável às apresentações } \\
\text { isoladas com menor } \\
\text { incidência de eventos } \\
\text { adversos }\end{array}$ & $\begin{array}{l}\text { Manual dos Centros de Referência } \\
\text { para Imunobiológicos Especiais } \\
\text { Guia prático de vacinas } 2016 / 2017 \\
\text { Guia prático de vacinas } 2017 / 2018\end{array}$ \\
\hline
\end{tabular}




\begin{tabular}{|c|c|c|c|c|}
\hline $\begin{array}{l}\text { Poliomielite } \\
\text { (VIP) }\end{array}$ & $\begin{array}{l}\text { A vacina é trivalente e contém } \\
\text { os vírus da poliomielite dos } \\
\text { tipos } 1,2 \text { e } 3 \text {, obtidos em } \\
\text { cultura celular e inativados por } \\
\text { formaldeído. Pode conter } \\
\text { traços de estreptomicina, } \\
\text { neomicina, polimixina e } 2- \\
\text { fenoxietanol como } \\
\text { conservante. }\end{array}$ & & & $\begin{array}{l}\text { Manual dos Centros de Referência } \\
\text { para Imunobiológicos Especiais } \\
\text { Guia prático de vacinas } 2016 / 2017 \\
\text { Guia prático de vacinas } 2017 / 2018\end{array}$ \\
\hline $\begin{array}{l}\text { Poliomielite } \\
\text { (VOP) }\end{array}$ & $\begin{array}{l}\text { Contém os três tipos de } \\
\text { poliovírus } 1,2 \text { e } 3 \text {. Tem como } \\
\text { adjuvante o cloreto de } \\
\text { magnésio e como conservantes } \\
\text { a estreptomicina e a } \\
\text { eritromicina. A vacina usada } \\
\text { no Brasil tem, atualmente, a } \\
\text { seguinte concentração de } \\
\text { partículas virais em cada dose: } \\
\text { • poliovírus tipo } 1: 1.000 .000 \\
\text { DICT50; } 1 \cdot \text { poliovírus tipo } 2: \\
\text { 100.000 DICT50; • poliovírus } \\
\text { tipo 3: } 600.000 \text { DICT50 }\end{array}$ & & & $\begin{array}{l}\text { Manual dos Centros de Referência } \\
\text { para Imunobiológicos Especiais } \\
\text { Guia prático de vacinas } 2016 / 2017 \\
\text { Guia prático de vacinas 2017/2018 }\end{array}$ \\
\hline Pneumocócica & $\begin{array}{l}\text { Vacina preparada a partir de } \\
\text { polissacarídeos capsulares } \\
\text { bacterianos purificados do } \\
\text { Streptococcus pneumoniae } \\
\text { (pneumococo), com } 10 \\
\text { sorotipos de pneumococo }(1,4 \text {, } \\
5,6 \mathrm{~B}, 7 \mathrm{~F}, 9 \mathrm{~V}, 14,18 \mathrm{C}, 19 \mathrm{~F} \mathrm{e} \\
23 \mathrm{~F}) .\end{array}$ & $\begin{array}{l}\text { Polissacarídeos dos sorotipos } \\
\text { 1, 3, 4, 5, 6A, 6B, 7, 9V, 14, } \\
\text { 18C, 19A, 19F, 23F; } \\
\text { conjugados ao CRM197 } \\
\text { (proteína diftérica). Contém } \\
\text { látex e alumínio. }\end{array}$ & $\begin{array}{l}\text { Polissacarídeos dos sorotipos } \\
\text { 1, 3, 4, 5, 6A, 6B, 7, 9V, 14, } \\
\text { 18C, 19A, 19F, 23F; } \\
\text { conjugados ao CRM197 } \\
\text { (proteína diftérica). Contém } \\
\text { látex e alumínio. }\end{array}$ & $\begin{array}{l}\text { Manual dos Centros de Referência } \\
\text { para Imunobiológicos Especiais } \\
\text { Guia prático de vacinas 2016/2017 } \\
\text { Guia prático de vacinas 2017/2018 }\end{array}$ \\
\hline Rotavírus & $\begin{array}{l}\text { A vacina é constituída por um } \\
\text { sorotipo do rotavírus humano } \\
\text { atenuado da cepa (RIX4414). } \\
\text { Apresenta como excipientes a } \\
\text { sacarose e o adipato dissódico. }\end{array}$ & $\begin{array}{l}\text { Vacina pentavalente de vírus } \\
\text { atenuado derivados de cepa } \\
\text { bovina com modificação } \\
\text { genética expressando G1, } \\
\text { G2, G3, G4 e P1A. Eficácia } \\
\text { para gastroenterite grave por }\end{array}$ & $\begin{array}{l}\text { Vacina pentavalente de vírus } \\
\text { atenuado derivados de cepa } \\
\text { bovina com modificação } \\
\text { genética expressando G1, } \\
\text { G2, G3, G4 e P1A. Eficácia } \\
\text { para gastroenterite grave por }\end{array}$ & $\begin{array}{l}\text { Manual dos Centros de Referência } \\
\text { para Imunobiológicos Especiais } \\
\text { Guia prático de vacinas } 2016 / 2017 \\
\text { Guia prático de vacinas 2017/2018 }\end{array}$ \\
\hline
\end{tabular}


rotavírus já demonstrada contra rotavírus $\mathrm{G} 1, \mathrm{G} 2, \mathrm{G} 3$, G4, G9 e P1A, em média, $90 \%$. rotavírus já demonstrada

contra rotavírus $\mathrm{G} 1, \mathrm{G} 2, \mathrm{G} 3$,

G4, G9 e P1A, em média,

$90 \%$.

\begin{tabular}{|c|c|c|c|c|}
\hline Meningocócica & $\begin{array}{l}\text { Polissacarídeos capsulares } \\
\text { purificados da Neisseria } \\
\text { meningitidis do sorogrupo C. } \\
\text { Tem como adjuvante o } \\
\text { hidróxido de alumínio. }\end{array}$ & $\begin{array}{l}\text { Polissacarídeos capsulares do } \\
\text { meningococo C conjugados à } \\
\text { toxina diftérica modificada } \\
\text { (Pfizer e Novartis) ou ao } \\
\text { toxoide tetânico (Baxter). } \\
\text { Contém Alumínio. }\end{array}$ & $\begin{array}{l}\text { Oligossacarídeos } \\
\text { meningocócicos } \mathrm{A}, \mathrm{C}, \mathrm{W} \text { e Y } \\
\text { conjugados à proteína } \\
\text { CRM197 de } C \text {. diphtheriae } \\
\text { ou TT toxoide tetânico }\end{array}$ & $\begin{array}{l}\text { Manual dos Centros de Referência } \\
\text { para Imunobiológicos Especiais } \\
\text { Guia prático de vacinas 2016/2017 } \\
\text { Guia prático de vacinas 2017/2018 }\end{array}$ \\
\hline Febre amarela & $\begin{array}{l}\text { Vírus vivos atenuados da febre } \\
\text { amarela derivados da linhagem } \\
17 \text { DD. Excipientes: sacarose, } \\
\text { o glutamato de sódio, o } \\
\text { sorbitol, a eritromicina e a } \\
\text { canamicina. }\end{array}$ & $\begin{array}{l}\text { Vacina de vírus vivo } \\
\text { atenuado Cepa 17D-204. } \\
\text { Imunogenicidade superior a } \\
95 \% .\end{array}$ & $\begin{array}{l}\text { Vacina de vírus vivo } \\
\text { atenuado Cepa 17D-204. } \\
\text { Imunogenicidade superior a } \\
95 \% \text {. }\end{array}$ & $\begin{array}{l}\text { Manual dos Centros de Referência } \\
\text { para Imunobiológicos Especiais } \\
\text { Guia prático de vacinas } 2016 / 2017 \\
\text { Guia prático de vacinas } 2017 / 2018\end{array}$ \\
\hline Tríplice viral & $\begin{array}{l}\text { Vírus vivos (atenuados) das } \\
\text { cepas Wistar RA } 27 / 3 \text { do vírus } \\
\text { da rubéola, Schwarz do } \\
\text { sarampo e RIT } 4385 \text {, derivada } \\
\text { de Jeryl Lynn, da caxumba. } \\
\text { Tem como excipientes } \\
\text { albumina humana, lactose, } \\
\text { sorbitol, manitol, sulfato de } \\
\text { neomicina e aminoácidos }\end{array}$ & $\begin{array}{l}\text { Cepas de vírus atenuados de } \\
\text { rubéola, sarampo e caxumba. } \\
\text { Contém traços de neomicina } \\
\text { e gelatina. }\end{array}$ & $\begin{array}{l}\text { Cepas de vírus atenuados de } \\
\text { rubéola, sarampo e caxumba. } \\
\text { Contém traços de neomicina } \\
\text { e gelatina. }\end{array}$ & $\begin{array}{l}\text { Manual dos Centros de Referência } \\
\text { para Imunobiológicos Especiais } \\
\text { Guia prático de vacinas 2016/2017 } \\
\text { Guia prático de vacinas 2017/2018 }\end{array}$ \\
\hline
\end{tabular}

Tabela 1: Composição das vacinas de rotina para crianças de até 12 meses nos anos de 2014 a 2018. 
De acordo com a tabela 1, é possível identificar a presença do timerosal na composição da vacina da Hepatite B em 2014 comparada aos outros anos. O conservante timerosal também estava presente na composição da vacina pentavalente apenas em 2014, em 2016 foi adicionada a neomicina e três vírus inativados da poliomielite. Na hexavalente também está presente o HBsAg a partir de 2016.

As vacinas da poliomielite só existiam isoladas até 2015, já que, a partir de 2016, passaram a fazer parte da vacina pentavalente.

No ano de 2016, foram adicionados os sorotipos 3, 6A e 19A de pneumococo à vacina pneumocócica, e a vacina rotavírus passou a ser composta por cinco sorotipos e não apenas um, como era em 2014. Já a vacina meningocócica passou a ser composta por oligossacarídeos meningocócicos $\mathrm{A}, \mathrm{C}, \mathrm{W}$ e Y e não apenas pelo subgrupo C, como era de 2014 a 2016. A cepa utilizada na vacina da febre amarela em 2014 era 17 DD e a partir de 2016 passou a ser utilizada a cepa 17D-204.

Os excipientes da vacina tríplice viral em 2014 eram albumina humana, lactose, sorbitol, manitol, neomicina e aminoácidos. Em 2016, a vacina passou a conter apenas traços de neomicina e gelatina em sua composição.

\section{Eventos adversos pós-vacinação}

\section{(EAPV)}

A partir dos dados do Sistema de Informações de Eventos Adversos PósVacinação (SI-EAPV) analisados por Pacheco et al. $(2018)^{13}$, nos anos de 2014 a 2016 houve notificação de 24.732 possíveis EAPV no Brasil, sendo as regiões Sudeste e Sul as mais incidentes. Apenas 1.622 casos foram encerrados no período do estudo. Cerca de $80 \%$ dos EAPV foram classificados como não graves e evoluíram para cura sem sequelas. Entre os eventos adversos graves, as manifestações clínicas sistêmicas neuronais corresponderam a mais de $50 \%$ dos sinais e sintomas. Seis casos evoluíram a óbito, mas sem que houvesse, necessariamente, uma relação causal com a vacinação.

Segundo o Boletim Epidemiológico de $2016^{8}$, o maior número de casos de EAPV teve relação com a vacina tríplice viral, além dos componentes das vacinas, outra possível causa dos EAPV se dá por erros na aplicação. Das manifestações em geral, mais de $70 \%$ apresentaram manifestações locais, sendo elas: dor, edema, calor, eritema ou rubor; e cerca de $50 \%$ apresentaram manifestações sistêmicas como febre, vômito, diarreia e sonolência. 
Alguns casos apresentaram os dois tipos de manifestação.

Não foi possível encontrar na literatura notificações ou informações sobre os EAPV nos anos de 2017 e 2018 no Brasil.

\section{Discussão}

O presente estudo evidenciou que a nível nacional apenas duas (BCG e tríplice viral) das 12 vacinas do esquema vacinal básico para crianças de até 12 meses obtiveram média de cobertura vacinal nos anos de 2014 a 2018 superior a 95\%, cobertura considerada satisfatória pelo Ministério da Saúde. Os dados corroboram com o estudo de Maciel et al. $(2019)^{14}$, realizado na cidade de Fortaleza com crianças menores de três anos. Em desacordo com o presente estudo, o Boletim Epidemiológico de $2015^{6}$ mostra que no período de 2004 a 2013 todas as vacinas apresentavam média de cobertura superior a 95\%, incluindo a Meningocócica C, introduzida em 2010 no calendário, que alcançou média de $100 \%$ no período de 2010 a 2013.

Segundo o Boletim Epidemiológico de $2019^{9}$, a média da cobertura vacinal da tríplice viral só foi superior a $95 \%$ no estado de
Pernambuco no período de 2016 a 2018. O presente estudo mostra que no Brasil a média do período de 2014 a 2018 foi de $97,21 \%$, sendo que apenas nos três primeiros anos esteve superior a $95 \%$.

O Boletim Epidemiológico de $2016^{8}$ mostra que a maior parte dos Eventos Adversos Pós-vacinação (EAPV) teve relação com a vacina tríplice viral, portanto, a diminuição da cobertura pode estar relacionada aos EAPV, e o número de novos casos de sarampo registrados nos últimos anos no Brasil também. Em 2014, os excipientes da vacina eram albumina humana, lactose, sorbitol, manitol, sulfato de neomicina e aminoácido, todavia, a partir de 2016 passaram a ser usados traços de neomicina e gelatina. Não se pode descartar a hipótese de uma relação entre a composição vacinal, os EAPV e a diminuição da cobertura vacinal. Além disso, chama-se a atenção para o fato de que, por alguns anos, a população não ouvia falar de doenças como o sarampo e, com isso, o estímulo a buscar a vacina como forma de proteção acabava diminuindo. Outro fator que deve ser levado em consideração, é a redução das campanhas e, consequentemente, menos espaço nas mídias.

A vacina para Febre Amarela foi, no geral, a que apresentou as menores médias de 
cobertura vacinal no período de 2014 a 2018, sendo a nacional $48,42 \%$. A menor foi a da região Nordeste $(35,66 \%)$ e a maior da região Centro-oeste $(88,77 \%)$. Essa vacina não é obrigatória para todo o território nacional por não ser endêmica em todas as regiões, por esse motivo há tanta discrepância em sua cobertura no território nacional ${ }^{15}$.

As maiores coberturas das vacinas de rotina presentes no Calendário Nacional de Vacinas para crianças de até 12 meses ocorreram na região Centro-oeste do Brasil, sendo que a menor média de cobertura da região no período de 2014 a 2018 foi de $82,74 \%$ (poliomielite $1^{\circ}$ reforço) e a maior 103,81\% (BCG). A região que obteve mais médias abaixo do preconizado pelo ministério da Saúde foi a Norte, sendo a menor delas $65,54 \%$ (Poliomielite $1^{\circ}$ reforço). A grande diferença de coberturas vacinais pode ter relação com desigualdades socioeconômicas, grau de escolaridade materno e a idade da criança, quanto maior a idade, menor a cobertura vacinal ${ }^{16,17}$. Além disso, a grande área da região norte, aliada às dificuldades de logística afetam diretamente a disponibilização de insumos necessários à vacinação.

A vacina da Hepatite B teve uma queda significante da cobertura nacional de 90,93\% em
2015 para $81,75 \%$ em 2016. A tabela 1 mostra que a partir de 2016 foi retirado o timerosal da vacina da Hepatite B, nos anos de 2017 e 2018 as coberturas vacinais nacionais foram superiores a $85 \%$. O timerosal é um antisséptico utilizado como conservante e muito se discute sobre seus efeitos tóxicos ao organismo devido à presença de etilmercúrio ${ }^{18}$. Em função disso, existem estudos mostrando uma possível relação do timerosal com casos de autismo e outras doenças neurológicas ${ }^{10}$. Semelhante ao fato supracitado, foi o que ocorreu com a vacina pentavalente, que também apresentava em sua composição o timerosal em 2014, sendo que sua cobertura vacinal nacional em 2015 era de 96,3\% e em 2016 passou para 89,27\%, em 2017 ainda houve queda $(83,78 \%)$, apresentando aumento da cobertura vacinal apenas em 2018 (85,94\%). A presença dessa subtância nas vacinas pode estar relacionada aos EAPV, o que justifica a diminuição da cobertura vacinal com posterior aumento após a sua retirada da composição daquelas onde se fazia presente ${ }^{7}$.

Até o ano de 2015, existiam as vacinas da Poliomielite isoladas, isso pode justificar a diminuição da média da sua cobertura vacinal, de modo que a cobertura vacinal nacional foi superior a 95\% apenas em 2014 e 2015. Por 
outro lado, a cobertura do reforço da vacina da Poliomielite foi inferior a $95 \%$ no período de 2014 a 2018.

Não foi observada relação da cobertura das demais vacinas com a sua composição e possíveis EAPV no período estudado.

A Organização Mundial da Saúde (OMS) recomenda que para manter as doenças erradicadas, é necessário que se mantenha uma cobertura vacinal igual ou superior a $95 \%$, sendo a vacina o único meio de combate a doenças imunopreveníveis ${ }^{19}$. Portanto, a principal consequência da queda da cobertura vacinal é o retorno de doenças erradicadas, principalmente o sarampo, que foi o mais observado nos últimos anos no Brasil. Dessa forma, é de suma importância que haja um engajamento multiprofissional, desde a orientação até a execução de atividades voltadas à vacinação, de forma que a população e os órgãos públicos tenham o real entendimento da necessidade e da importância das vacinas para a saúde humana.

\section{Conclusão}

Constatou-se que apenas duas (BCG e tríplice viral) das 12 vacinas tiveram cobertura satisfatória a nível nacional, sendo que a região Centro-oeste apresentou as maiores coberturas e as regiões Norte e Sul apresentaram as menores.
No geral, a partir do ano de 2016 observaram-se quedas na cobertura vacinal, podendo estar relacionado com questões socioeconômicas e com os Eventos Adversos Pós-Vacinação. Estes podem ser decorrentes de erros na aplicação e reações a componentes das vacinas. A principal consequência da queda da cobertura vacinal é o retorno de doenças erradicadas, tomando como exemplo o sarampo que apresentou inúmeros casos nos últimos anos, no Brasil.

Considerando que as vacinas são os imunobiológicos mais seguros e de grande importância para a saúde da população em geral, principalmente das crianças, é necessário promover a conscientização da população por meio de campanhas de vacinação e informações sobre a importância de receber as vacinas, bem como alertar sobre os possíveis eventos adversos e a como prosseguir caso esses ocorram.

\section{Referências}

1. Ministério da Saúde. Manual dos Centros de Referência para Imunobiológicos Especiais. $4^{\mathrm{a}}$ ed. Brasília: 2014. Secretaria de Vigilância em Saúde. Departamento de Vigilância das doenças transmissíveis. [acesso 14 set. 2019] Disponível em: http://www.saude.pr.gov.br/arquivos/File/01VACINA/manual crie.pdf

2. Ministério da Saúde. Revista da Vacina. Brasília: s/d. Ministério da Saúde. Centro Cultural da Saúde. [acesso 12 set. 2019] Disponível em: http://www.ccms.saude.gov.br/revolta/pdf/M7.p $\underline{\mathrm{df}}$ 
3. Ministério da Saúde. Manual de Normas e Procedimentos Para Vacinação. Brasília: 2014. Programa Nacional de Imunizações. [acesso 14 set. 2019] Disponível em: http://bvsms.saude.gov.br/bvs/publicacoes/man ual procedimentos vacinacao.pdf

4. Queiroz L, Monteiro S, Mochel E, Veras M, Sousa F, Bezerra, M, et al. Cobertura vacinal do esquema básico para o primeiro ano de vida nas capitais do Nordeste brasileiro. Cadernos de Saúde Pública. 2013;29(2):294-302.

5. Ministério da Saúde. Calendário Nacional de Vacinação. Brasília: s/d. Programa Nacional de Imunizações. [acesso 12 set. 2019.] Disponível em: http://www.saude.gov.br/saudede-a-z/vacinacao/calendario-vacinacao\#

6. Ministério da Saúde. Programa Nacional de Imunizações: aspectos históricos dos calendários de vacinação e avanços dos indicadores de coberturas vacinais, no período de 1980 a 2013. Brasília: 2015. [acesso 14 set. 2019] Disponível em: https://portalarquivos2.saude.gov.br/images/pdf /2015/outubro/14/besvs-pni-v46-n30.pdf

7. Piacentini, S; Contrera-Moreno, L. Eventos adversos pós-vacinais no município de Campo Grande (MS, Brasil). Ciência \& Saúde Coletiva. 2011;16(2): 531-536.

8. Ministério da Saúde. Perfil epidemiológico dos casos notificados dos erros de imunização, Brasil 2016. Brasília: 2018. [acesso 14 set. 2019] Disponível em: https://portalarquivos2.saude.gov.br/images/pdf /2018/novembro/21/2018-028.pdf

9. Ministério da Saúde. Vigilância Epidemiológica do sarampo no Brasil, Semanas Epidemiológicas 23 a 34 de 2019. Brasília: 2019. [acesso 19 set. 2019] Disponível em: https://portalarquivos2.saude.gov.br/images/pdf 12019/agosto/28/BE-2019-24-Sarampo-

28ago19-prelo.pdf

10. Da Silva Pires V. Timerosal contido em vacinas e transtornos do espectro autista: revisão de literatura. SANARE- Revista de Políticas Públicas. 2018;17(1):1-9.

11. Sociedade Brasileira de imunização. Guia prático de Vacinas 2016/2017. Brasília: 2017. Ministério da Saúde. [acesso em 14 set. 2019] Disponível em: http://www.epi.uff.br/
12. Sociedade Brasileira de imunização. Guia prático de Vacinas 2017/2018. Brasília: 2018. Ministério da Saúde. [acesso em 14 set. 2019] Disponível em: http://www.epi.uff.br/

13. Pacheco F, Domingues C, Maranhão A, Carvalho S, Teixeira A, Braz R, et al. Análise do Sistema de Informação da Vigilância de Eventos Adversos Pós-vacinação no Brasil, 2014 a 2016. Revista Panamericana de Salud Pública. 2018;42(12):1-8.

14. Maciel J, Cavalcante A, Campos J, Correia L, Rocha H, Rocha S, et al. Análise do estado de cobertura vacinal de crianças menores de três anos no município de Fortaleza em 2017. Revista Brasileira de Medicina de Família e Comunidade. 2019;14(41):1824.

15. Ministério da Saúde. Febre Amarela: Ministério da Saúde atualiza casos no país. Brasília: 2019. [acesso 08 nov. 2019] Disponível em: http://www.saude.gov.br/noticias/agenciasaude/42940-febre-amarela-ministerio-da$\underline{\text { saude-atualiza-casos-no-pais-6 }}$

16. Nunes D, de Menezes F, Igansi C, de Araújo W, Segatto $\mathrm{T}$, Costa K, Wada M. Inquérito da cobertura vacinal de tríplice viral e tríplice bacteriana e fatores associados à não vacinação em Santa Maria, Distrito Federal, Brasil 2012. Revista Pan-Amazônica de Saúde. 2018;9(1):1-9.

17. Castro A, Veras A, Bernardo A, Ventura M, Caminha M, Silva M, et al. Fatores associados à cobertura vacinal em criançasanálise de uma comunidade. Artigo de PIBIC. Faculdade Pernambucana de Saúde; 2018.

18. Carneiro M. Avaliação da distribuição, metabolismo e nefrotoxicidade do timerosal-um conservante a base de mercúrio usado em vacinas-utilizando modelos in vivo e in vitro. Tese de doutorado. Universidade de São Paulo; 2014.

19. Ferreira R, de Sousa J, Santos J, da Silva $\mathrm{S}$, da Rosa A, da Costa J et al. Correlação entre cobertura vacinal e notificações por sarampo no Distrito Federal. REAS [Internet]. 1nov.2019 [citado 8nov.2019];11(17):e1654. Available from:

https://www.acervomais.com.br/index.php/saud e/article/view/1654

Data de submissão: 30/11/2019 
Acta Elit Salutis- AES - (ano) volume (número) ISSN online XXXXXX-Artigo Original 